\title{
Muscle-sparing aortic coarctation repair
}

\author{
Stephanie G. Berset, MD, ${ }^{\mathrm{a}}$ Hitendu Dave, MD, ${ }^{\mathrm{b}}$ Christian Balmer, MD, ${ }^{\mathrm{b}}$ Anna Nowacka,
} Raymond Pfister, MD, ${ }^{\mathrm{d}}$ Patrick O. Myers, $\mathrm{MD},{ }^{\mathrm{d}}$ and René Prêtre, $\mathrm{MD}^{\mathrm{d}}$

\section{ABSTRACT}

Objective: Surgery for aortic coarctation repair provides excellent hemodynamic results but may be complicated by musculoskeletal issues. The purpose of the study was to determine the midterm results of a muscle-sparing surgical approach to aortic coarctation repair, with special emphasis on the repair and on the musculoskeletal changes associated with a posterior thoracotomy.

Methods: We included all children with aortic coarctation operated on with our minimally invasive approach between June 2002 and October 2004, with a follow-up of $\geq 4.5$ years. Patients were assessed clinically and echocardiographically. The spine, left chest, and shoulder were assessed clinically and radiographically.

Results: Thirty-one children were included. The age at operation ranged from 1 day to 15 months and weight ranged from $980 \mathrm{~g}$ to $10 \mathrm{~kg}$. All patients underwent an extended end-to-end anastomosis coarctation repair through a minimal $(n=19)$ or total-muscle sparing $(n=12)$ or extrapleural $(n=18)$ approach. Five patients had an additional enlargement procedure on the aortic arch. 27 patients had no residual or recurrent gradient. Four patients exhibited restenosis, for which 1 underwent a percutaneous angioplasty and 2 underwent surgical reintervention. All patients were free of hypertension. One patient had borderline values. The musculoskeletal assessment was normal in all but 3 patients. Two patients who underwent other subsequent thoracic surgeries developed thoracogenic scoliosis of moderate severity. A third patient had a left winged scapula. No rib fusion or intercostal space enlargement was found.

Conclusions: Compared with a conventional approach, our minimally invasive surgical approach led to excellent musculoskeletal outcomes without compromising the hemodynamic results. (JTCVS Techniques 2020;3:249-56)

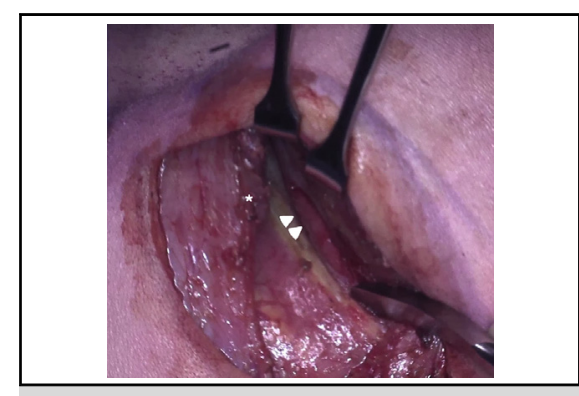

The latissimus dorsi $\left(^{*}\right)$ has been mobilized and preserved, and the tip of the scapula is retracted cephalad. The intercostal space is entered by separating the periosteum is separated from the superior border of the fifth rib (white arrows) without dividing any intercostal muscles.

\section{CENTRAL MESSAGE}

Compared with a conventional approach, our minimally invasive approach, which respects the chest wall muscles, results in excellent musculoskeletal outcomes without compromising the hemodynamic results of coarctation repair.

\section{PERSPECTIVE}

The goal of surgical treatment of aortic coarctation is to relieve the pressure gradient and allow for subsequent growth. Coarctation resection and extended end-to-end anastomosis has become the surgical gold standard. Early and long-term results are excellent. Minimizing the trauma of surgery through a less invasive approach, allows quicker post-operative recovery. This can be achieved by avoiding division of any muscles and by entering the chest with a subperiosteal and extrapleural route.

See Commentary on page 257 .

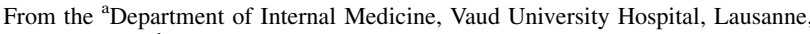
Switzerland; 'Department of Cardiology, Zurich University Children's Hospital, Zurich, Switzerland; ' Department of Cardiovascular Surgery, Valais Hospital, Sion, Switzerland; and ${ }^{\mathrm{d}}$ Department of Cardiovascular Surgery, Vaud University Hospital, Lausanne, Switzerland.

Read at the Joint Annual Meeting of the Swiss Society of Cardiology and Cardiac Surgery in Baden, Switzerland, June 8, 2017.

Received for publication April 29, 2020; revisions received April 29, 2020; accepted for publication May 8, 2020; available ahead of print 17 May, 2020.
}

\footnotetext{
Address for reprints: René Prêtre, Service de Chirurgie Cardiaque, CHUV, Rue du Bugnon 46, CH-1011 Lausanne, Vaud, Suisse (E-mail: rene.pretre@chuv.ch); or Stephanie G. Berset, Service de Médecine Interne, CHUV, Rue du Bugnon 46, CH-1011 Lausanne, Vaud, Suisse (E-mail: stephanie.berset@chuv.ch). 2666-2507

Copyright (C) 2020 The Authors. Published by Elsevier Inc. on behalf of The American Association for Thoracic Surgery. This is an open access article under the CC BY license (http://creativecommons.org/licenses/by/4.0/). https://doi.org/10.1016/j.xjtc.2020.05.005
} 
Video clip is available online.

The goal of surgical treatment of aortic coarctation is to relieve the pressure gradient and allow for subsequent growth. Coarctation resection and extended end-to-end anastomosis has become the surgical gold standard. Early and long-term results are excellent. Minimizing the trauma of surgery through a less invasive approach allows for quicker postoperative recovery. This can be achieved by avoiding the division of any muscles and by entering the chest via a subperiosteal and extrapleural route.

In 2002, we introduced a total muscle-sparing surgical approach to minimize the trauma of surgery, and have previously reported our initial experience and hemodynamic results. ${ }^{1}$ Although minimizing trauma is important, priority is given to achieving a flawless repair without residual gradient. Fewer studies have investigated the musculoskeletal outcomes after coarctation repair. Conventional posterior thoracotomy, the most commonly used approach to coarctation, leads to a high rate of postoperative winged scapula (in up to $77 \%$ of patients) or scoliosis (up to $46 \%$ of patients). ${ }^{2-5}$

The goal of this study was to determine the midterm results of our total muscle-sparing and extrapleural approach to coarctation, with a special emphasis on the aortic repair and on the musculoskeletal changes linked to the posterior thoracotomy. Our hypothesis was that this minimally invasive approach performed at a young age, while ensuring an excellent repair, could lead to better musculoskeletal outcomes compared with those published in the literature.

\section{METHODS \\ Patient Inclusion}

We performed a retrospective review of all consecutive neonates, infants, and children who underwent with a muscle-sparing aortic coarctation repair by a single operator between June 2002 and October 2004. We chose this cohort to ensure a minimum 4.5-year follow-up to assess musculoskeletal outcomes. This cohort was previously reported in our description of the technique and initial hemodynamic results. ${ }^{1}$ The exclusion criterion was a follow-up $<4.5$ years.

Our research plan was accepted by the Swiss Ethics committee (protocol no. 2016-00713). The Swiss Ethics Committee approved that this study be carried out without consent forms thanks to article 34 of the Swiss federal law on human research. Regarding the pictures and the video of the patient, a proper consent form was obtained from the legal representative.

\section{Surgical Technique}

The surgical technique has been described in detail previously. ${ }^{6}$ The patient is positioned in a right lateral decubitus, turned slightly forward (Figures 1, A, and 2). The left arm is rotated forward and upward. The incision is made on the skin facing the so-called "triangle of auscultation," beginning 1 to $2 \mathrm{~cm}$ under the inferior angle of the scapula and directed posteriorly toward the spine (Figure 1, B). The length of the incision is related to the size of the patient, but in our series of neonates and small infants it never exceeded 5 to $6 \mathrm{~cm}$. The subcutaneous tissue is undermined over an extensive area to allow visualization of the spinal insertion of the latissimus dorsi. At the beginning of our experience, the posterior part of the latissimus dorsi was divided over several centimeters. With further undermining of the subcutaneous tissue posteriorly, the entire muscle could be preserved, and this has been our approach ever since. The border of this muscle is detached from its aponeurosis for 6 to $7 \mathrm{~cm}$, up to the tip of the scapula. One right-angle retractor is inserted below the latissimus dorsi and the serratus anterior, and another is inserted below the scapula. The loose tissue between the thoracic wall and the muscles is freed, allowing better visualization of the fifth intercostal space (Figure 1,C).

The intercostal muscles are preserved by peeling the periosteum from the upper side of the fifth rib, by opening the periosteum with lowenergy cautery along the superior border of the rib as far as possible anteriorly. The erector spinae muscles are preserved posteriorly. The periosteum is separated from the rib with a periosteum elevator. The parietal pleura is freed from the thoracic wall with 2 peanut sponges. This maneuver is extended laterally down to the aorta and superiorly to the aortic arch. A small retractor is introduced and opened progressively. Further freeing of the periosteum and of the pleura is performed if necessary to avoid excessive tension on the ribs. The pleura, and the left lung indirectly, are retracted medially with several $6 / 0$ polypropylene stitches inserted in the pleura, close to the aorta. This exposes the thoracic aorta without the need to introduce a classical retractor, which frees the hand of the assistant. The aortic arch and the arch vessels are dissected completely free. The descending aorta and the thoracic arteries are also dissected free as low as possible. The first 2 pairs of intercostal arteries are mobilized over their entire length, to allow sufficient mobilization of the descending thoracic aorta. They are clipped, because the distal clamp will be placed below their level, but not divided, because they usually can be preserved. The clips are removed at the end of the coarctation repair.

After administration of heparin, the aortic arch is clamped between the brachiocephalic trunk and the common carotid artery, as is the descending aorta. The left carotid artery, left subclavian artery, and first 2 pairs of thoracic arteries were temporarily softly occluded with a hand-held clipper (Figures 3 and 4). The ductus arteriosus is ligated and divided. The coarctation of the aorta is resected. The aortic arch is opened inferiorly up to the proximal clamp, below the takeoff of the left common carotid artery. The descending aorta is shaped to fit this long opening. The distal aortic arch and the proximal descending aorta are sewn together with a running 70 or 6-0 polydioxanone suture (Figure 5).

In patients with pronounced hypoplasia of the aortic arch, the arch is enlarged superiorly with a patch of autologous pericardium, while the lower body is perfused by the ductus arteriosus. The coarctation resection and a direct aortic anastomosis are performed after the arch plasty. ${ }^{7}$

Air is removed from the aorta, and the clamps (including the clips on the left subclavian, left common carotid and the intercostal arteries) are removed. A low-vacuum drain is placed in the extrapleural space. The chest wall is reconstructed by reapproximating the peeled-off periosteum onto the bare rib bed using a running polyglactin $2-0$ or 3-0 suture. We have never encountered the rib vessels, which run in a groove. This method of closure ensures preservation of the normal rib interspace, because almost no muscle is taken in the bites. The loose tissue below the muscle plane is closed with a fine Vicryl suture. The latissimus dorsi is approximated to its aponeurosis (Figure 1,D). A 2-layer absorbable suture closes the skin (Video 1).

\section{Follow-up and Clinical Assessment}

Patients were followed-up through their referring cardiologist and by reviewing their last report. Patients followed for $<4.5$ years were excluded.

The quality of the aortic repair was assessed by coarctation recurrence and persistent hypertension. Recurrence was defined as a pressure gradient of $\geq 20 \mathrm{~mm} \mathrm{Hg}$ across the aortic repair or the need for an endovascular or surgical reintervention. Blood pressure $>95$ th percentile or $>140 / 90 \mathrm{~mm}$ $\mathrm{Hg}$ was considered hypertension. Both upper and lower limb blood 


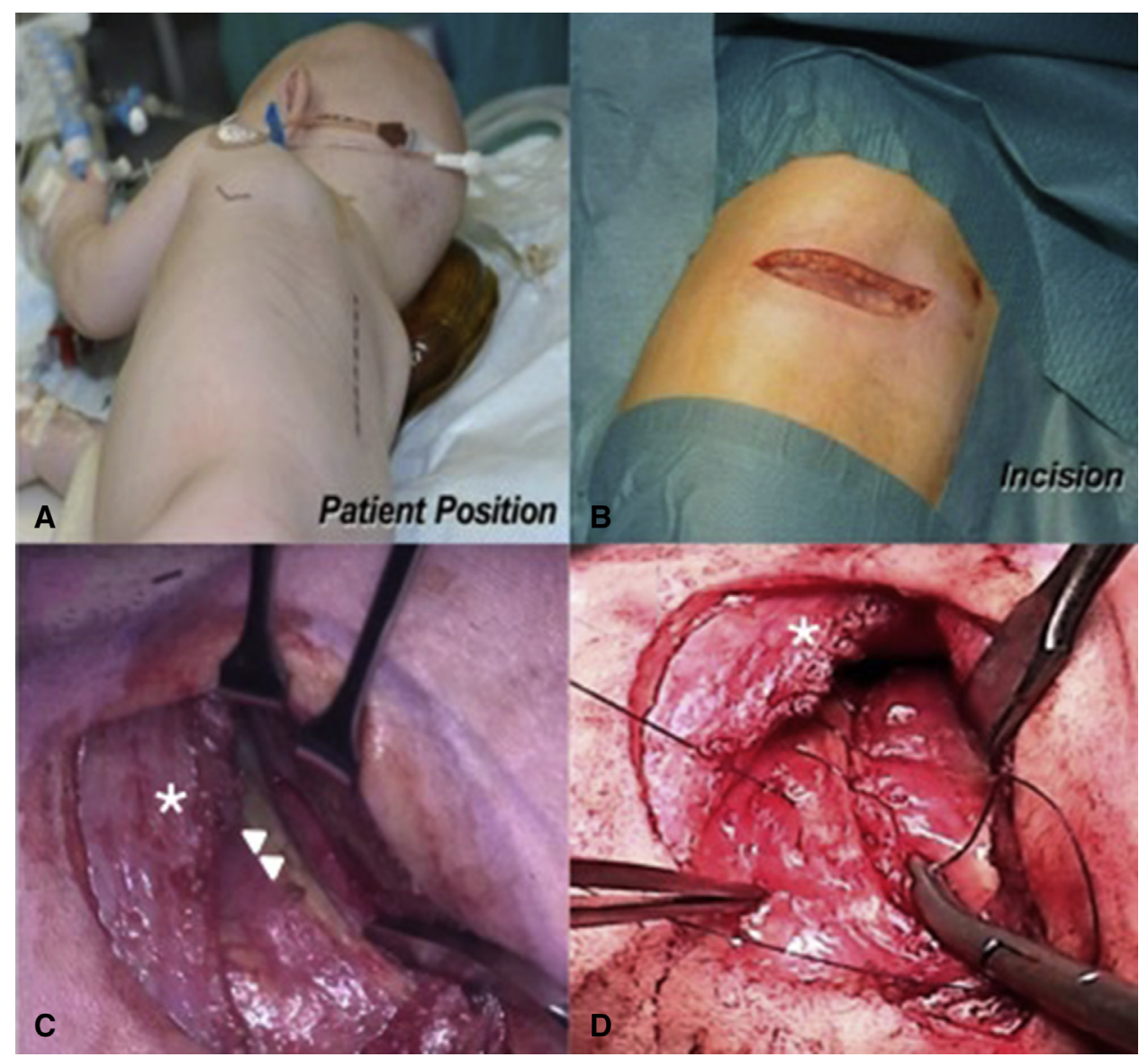

FIGURE 1. A, Position of the patient before surgery. The dashed line marks the spine. The solid line shows the tip of the scapula. B, Subscapular incision of $5 \mathrm{~cm}, 1 \mathrm{~cm}$ under the medial border of the scapula. C, The latissimus dorsi $(*)$ has been mobilized and preserved, and the tip of the scapula is retracted cephalad. The intercostal space is entered by separating the periosteum is separated from the superior border of the fifth rib (white arrows) without dividing any intercostal muscles. D, Reconstruction of the intercostal space. The periostium is sutured using a running suture to the rib.

pressure were measured by standard pressure cuffs at the practitioner's office. In borderline patients, 24-hour ambulatory blood pressure was measured.

The status of the left chest and shoulder was assessed clinically and radiographically. The symmetry of the thorax and shoulder was evaluated, with a special emphasis on the recognition of scoliosis and abnormal position of the scapula. Rib fusion or excessive width of the intercostal space was considered a failure. Whenever an anomaly was suspected, a more complete examination was performed by an orthopedic surgeon.

This study relied on descriptive statistics using Excel (Microsoft, Redmond, Wash). Kaplan-Meier estimates were calculated using SPSS version 25 (IBM, Armonk, NY) and GraphPad Prism (GraphPad Software, La Jolla, Calif).

\section{RESULTS}

\section{Patient Population}

Forty patients underwent coarctation repair during the study period. Nine patients were excluded due to followup below our prespecified minimum $(<4.5$ years $)$ for an adequate musculoskeletal assessment. Four of these patients had insufficient follow-up, and 5 died from associated diseases, either cardiac (ie, Shone's complex, endocardial fibroelastosis, or intractable pulmonary hypertension) or noncardiac (ie, diaphragmatic hernia or hypoplasia of the right lung). Thus, a total of 31 patients were included in the study; the baseline characteristics of these patients are summarized in Table 1.

\section{Surgical Technique}

All patients underwent an extended end-to-end anastomosis; 5 patients required an additional enlargement plasty of the aortic arch. In 19 patients, surgical access to the aorta included a minimally invasive posterior thoracotomy with division of the posterior part of the latissimus dorsi for 2 to $3 \mathrm{~cm}$. A total muscle-sparing posterior thoracotomy was performed in 12 patients. In all patients, the intercostal space and muscles were preserved by the subperiosteal access. In 18 patients, the approach was extrapleural. ${ }^{1}$ Operative data and concomitant procedures are summarized in Table 2.

\section{Follow-Up}

During a mean follow-up of $11.2 \pm 1.5$ years, 1 patient died at age 11 years of pulmonary hypertension after 


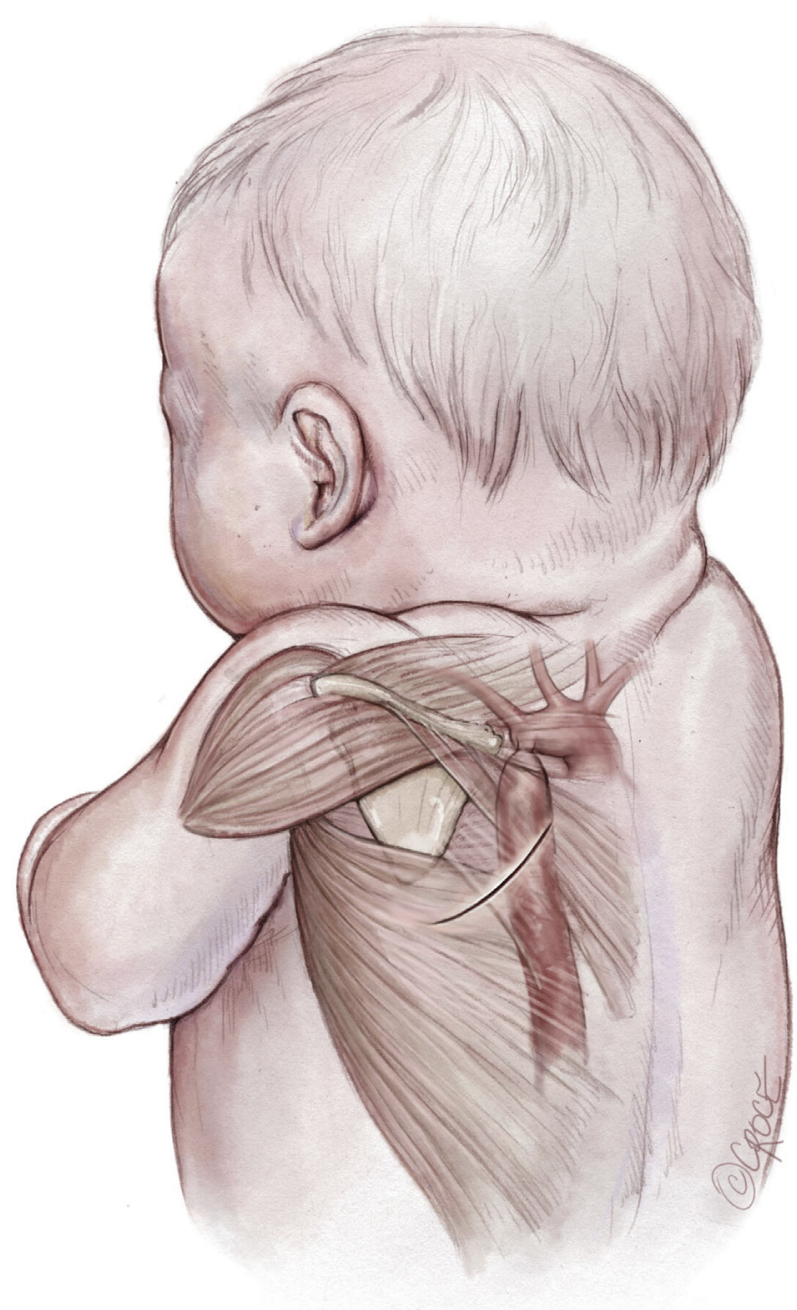

FIGURE 2. The position of the coarctation of the aorta in the chest. The solid line under the scapula shows the incision location.

repeated bronchoaspiration and in a context of multiple contraindications for lung transplantation. This patient had never needed a reintervention regarding the coarctation.

\section{Hemodynamic Outcomes}

Twenty-seven patients showed an excellent result, with no residual or recurrent stenosis $(87.1 \%))^{5}$ Four patients showed a residual gradient $(>20 \mathrm{~mm} \mathrm{Hg}$ at rest), for which 1 patient underwent balloon angioplasty and 2 patients underwent a second surgical repair (Figure 6).

Patient A required balloon angioplasty because of a 26$\mathrm{mm} \mathrm{Hg}$ peak gradient across the isthmus and stenosis of the left subclavian artery origin. Patient B presented with a $25-\mathrm{mm} \mathrm{Hg}$ gradient across the proximal aortic arch between the brachiocephalic artery and the left common carotid artery; this was repaired surgically by patch enlargement of the inferior part of the arch through a sternotomy and using cardiopulmonary bypass. ${ }^{8}$ The patient showed a

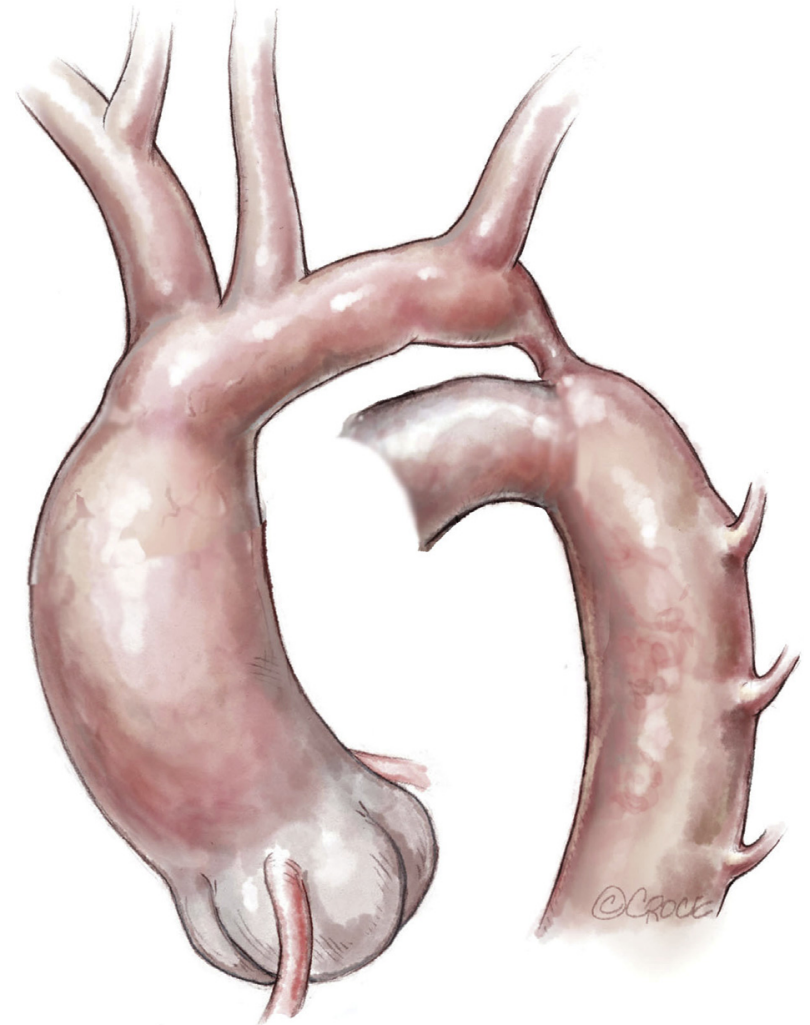

FIGURE 3. Neonatal ductus-dependent coarctation of the aorta with an elongated and hypoplastic distal arch (between the left common carotid and the left subclavian arteries), a stenotic isthmus, and a ductus arteriosus extending into the descending aorta.

subsequent wide aortic arch without any gradient across the arch or the isthmus. Patient $\mathrm{C}$ underwent a surgical reintervention because of a $27-\mathrm{mm} \mathrm{Hg}$ gradient across the distal aortic arch. Reoperation consisted of a superior arch enlargement with a subclavian artery flap (a reverse Waldhausen procedure) and reimplantation of the distal left subclavian artery in the left carotid artery, at the thoracic outlet. Patient D showed a stable $21 \mathrm{~mm} \mathrm{Hg}$ gradient across the aortic arch and was not reoperated on. Transthoracic echocardiography showed a good repair result at 10 years and a mild turbulent flow acceleration just after the left subclavian artery takeoff that had been stable over the years, with no hemodynamic consequences. This patient had normal blood pressure values.

In terms of blood pressure, all patients showed normal values except patient $C$, who showed a tendency to have values $>95$ th percentile. No patient was receiving antihypertensive medication.

\section{Musculoskeletal Outcomes}

All the patients for whom detailed orthopedic data were obtained $(\mathrm{n}=25)$ had good mobility of the back and left shoulder at midterm follow-up, with the exception of 1 


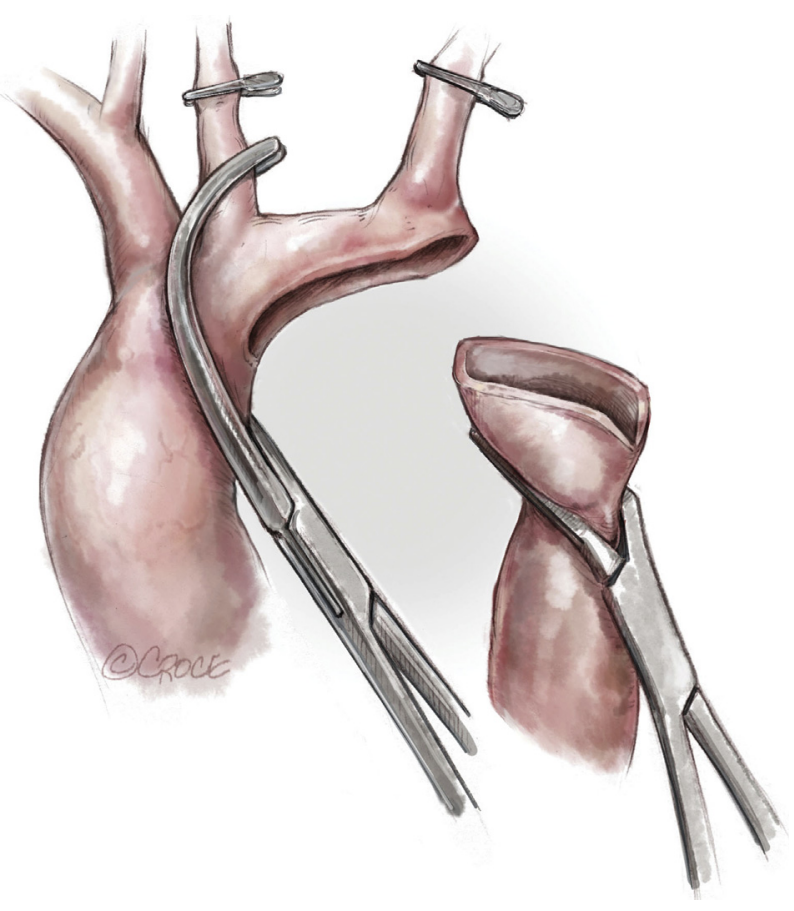

FIGURE 4. Clamping of the aortic arch between the brachiocephalic trunk and the common left carotid artery. The left subclavian and the left common carotid arteries are clamped by hand-held clips. The ductus arteriosus is ligated and divided. The coarctation is resected. The underside of the aortic arch is fileted open, and a counterincision is made in the opposing proximal descending aorta to allow an extended end-to-end anastomosis.

patient, in whom this was not reported. The alignment of the thoracolumbar spinous processes was within the normal range in all but 2 patients $(7.4 \%)$. One patient had a lumbar (L2) left-convex scoliosis of $25^{\circ}$ with a thoracic (T8) rightconvex scoliosis of $28^{\circ}$ and pectus excavatum at 12.5 years. This patient, who presented with a double-outlet right ventricle, had undergone a posterolateral thoracotomy using a partial muscle-sparing thoracotomy approach with division of the posterior part of the latissimus dorsi over several centimeters. The operation included coarctation of the aorta repair and a pulmonary artery banding at age 2 days and a sternotomy 4 months later for the removal of a pulmonary artery band and closure of a ventricular septal defect and an atrial septal defect. The other patient had a right-convex thoracolumbar scoliosis of $24^{\circ}$ at 9.5 years. Within the first 2 days of life, he had undergone a right lateral thoracotomy (without muscle preservation) to correct esophageal atresia and a left posterior thoracotomy using a total muscle-sparing and extrapleural approach for the coarctation repair. The correction of the aorta included a subclavian flap plasty and reimplantation of the left subclavian artery onto the left common carotid.

Twenty-eight patients had normal shoulder motion and a normal shoulder appearance. One patient had a left winged scapula $(3.6 \%)$ with normal shoulder motion. He

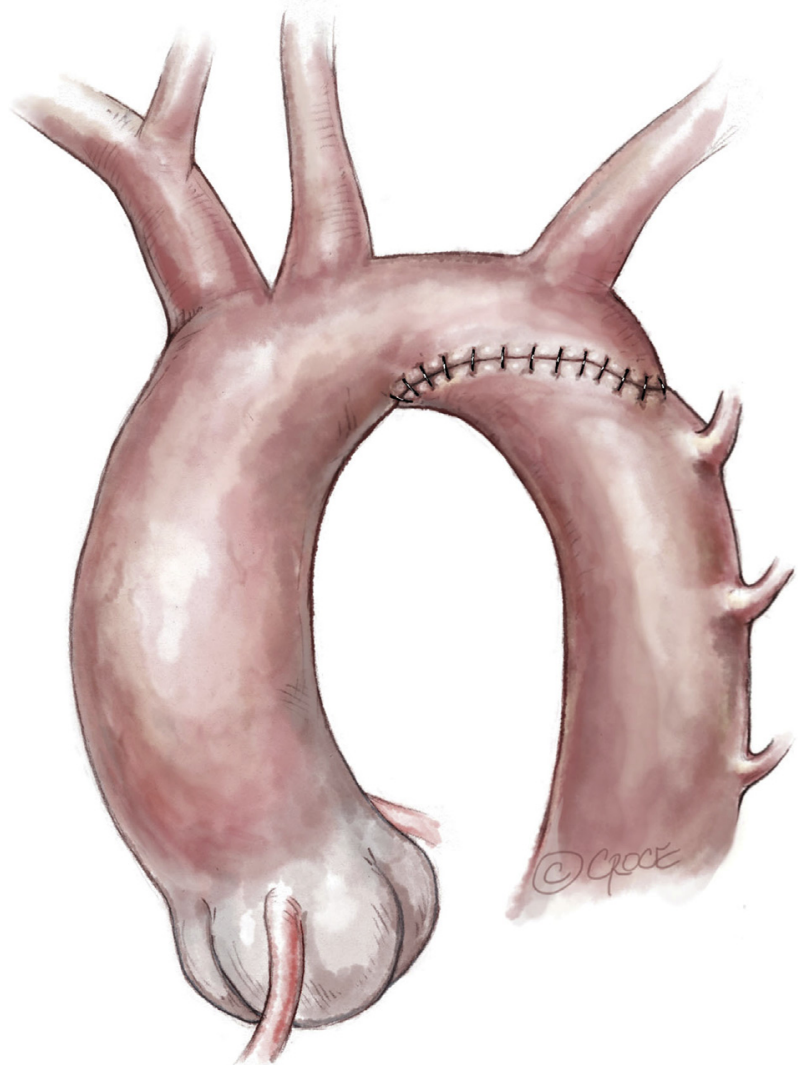

FIGURE 5. The distal aortic arch and the proximal descending aorta are anastomosed with a running 7-0 or 6-0 polydioxanone suture.

had undergone repair of coarctation of the aorta with left subclavian artery translocation, using a partial musclesparing approach, at 8 days of age and was the patient who required balloon angioplasty 3 months later for restenosis.

All chest radiographs showed normal rib cage anatomy, without any rib fusion or excessive enlargement of the intercostal space.

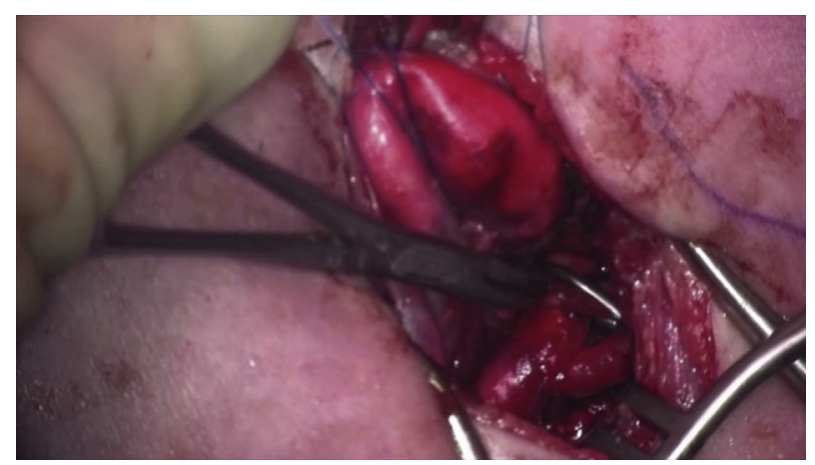

VIDEO 1. Our technique of muscle-sparing coarctation repair. Video available at: https://www.jtcvs.org/article/S2666-2507(20)30226-1/fulltext. 
TABLE 1. Baseline patient characteristics

\begin{tabular}{lc}
\hline \multicolumn{1}{c}{ Characteristic } & Value \\
\hline $\begin{array}{l}\text { Sex, female/male, } \mathrm{n} \\
\text { Age at operation, d, median (IQR) }\end{array}$ & $9 \mathrm{~d}(5-30,16$ \\
$\begin{array}{l}\text { Weight at operation, median } \\
(\mathrm{IQR})\end{array}$ & $3480 \mathrm{~g}(2900-3910 \mathrm{~g}, 980 \mathrm{~g}-10 \mathrm{~kg})$ \\
$\begin{array}{l}\text { Duct-dependency, } \mathrm{n}(\%) \\
\text { Associated disease, } \mathrm{n}(\%)\end{array}$ \\
$\begin{array}{l}\text { Previous balloon angioplasty, } \\
\mathrm{n}(\%) *\end{array}$ \\
$\begin{array}{l}\text { IQR, Interquartile range. } * \text { The coarctation was slightly dilated to reach a concomitant } \\
\text { aortic valve stenosis to dilate the aortic valve. The surgical repair of the coarctation } \\
\text { was performed within 2 weeks. }\end{array}$
\end{tabular}

\section{DISCUSSION}

With increasingly less-invasive repairs and progress in interventional cardiology, our goal was to determine the benefits of a minimally invasive surgical approach, focusing on the midterm results with special emphasis on the surgical repair of the aorta and on the musculoskeletal changes associated with posterior thoracotomy. Our minimally invasive approach showed excellent hemodynamic results and a superior outcome in terms of shoulder and back appearance and mobility compared with a conventional approach, as summarized in Table 3.

\section{Quality of the Aortic Repair}

Ensuring the quality of aortic repair is our central concern. Hypertension is one of the major predictors of long-term survival. ${ }^{9,10}$ It may occur in up to $45 \%$ of patients after surgical repair, although surgery during infancy reduces the risk down to approximately $10 \%$. Our minimally invasive approach shows results comparable to those from a conventional approach. In our cohort, only 1 patient $(3.2 \%)$ showed a trend toward hypertension $>95$ th percentile, and no patient required any antihypertensive treatment. Our restenosis rate of $12.9 \%$ is comparable to rates reported by other groups performing this correction in the neonatal period. ${ }^{11-13}$ Of note, in 3 of the 4 patients with recurrent obstruction, the narrow part of the aorta was in the proximal aortic arch (between the brachiocephalic artery and the left common

TABLE 2. Operative data

\begin{tabular}{lc}
\hline \multicolumn{1}{c}{ Parameter } & Value \\
\hline Operative time, min, median (IQR) & $90(80-120)$ \\
Cross-clamp time, min, median (IQR) & $22(20-29.25)$ \\
Procedure, $\mathrm{n}$ & \\
Extended end-to-end anastomosis & 31 \\
Pulmonary artery banding & 5 \\
Enlargement-plasty of the distal arch & 4 \\
Subclavian retrograde flap plasty & 1 \\
\hline$I Q R$, Interquartile range. &
\end{tabular}

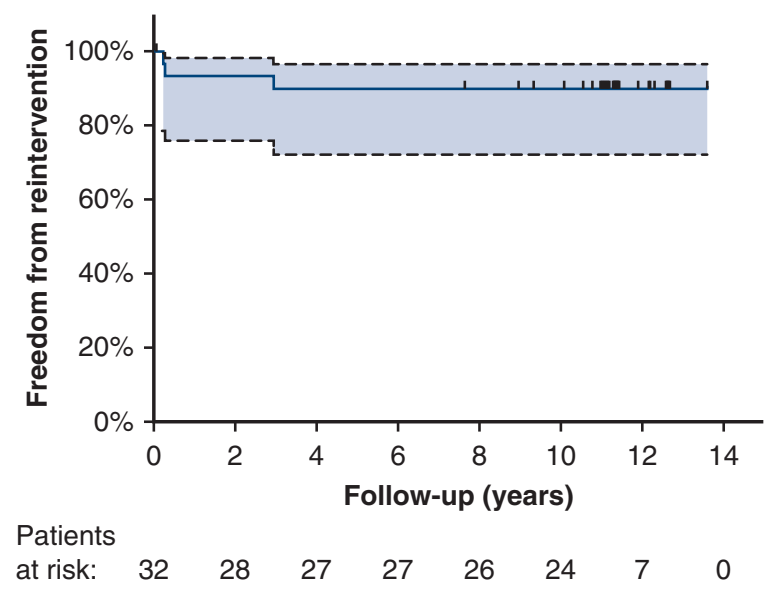

FIGURE 6. Kaplan-Meier estimates of freedom from reintervention up to 14 years.

carotid artery), which could be relieved in 2 patients with an arch plasty through a sternotomy. In 1 patient, stenosis recurred at the level of the repair and necessitated balloon dilatation. Overall, our results demonstrate that our minimally invasive approach allowed us to perform an extended resection of the coarctation of the aorta in all patients, with the same outcome.

\section{Musculoskeletal Outcome}

Depending on the authors and on the method of diagnosis, the estimated prevalence of scoliosis in the population presenting with congenital cardiac diseases, is reported to range between $0.2 \%$ and $31 \%$, compared with a rate of $2 \%$ or $3 \%$ in the general population. ${ }^{2,4,5,14-16}$ Similarly, Reckles and colleagues ${ }^{17}$ found that among a cohort of patients with scoliosis, $5 \%$ had a cardiac congenital defect, a 10-fold higher rate than that in the general population. Although the relationship is still unclear, some major etiologic factors include the variety of cardiac congenital diseases, genetic predisposition, and the surgical approach possibly leading to thoracogenic scoliosis., ${ }^{2,4}$ Other studies showed that patients with cyanotic cardiac disorders tended to show a higher prevalence of scoliosis, suggesting that hypoxia may be involved in its genesis. ${ }^{3,4,17}$ Obviously, mechanical causes after surgery (eg, rib resection, rib fusion, muscles division, and consequent nerves injury-anything that weakens and deforms the chest wall) can account for such a subsequent development. According to Van Biezen and colleagues, ${ }^{5}$ eliminating the function of the intercostal muscles has the same effect as a paralysis and weakens the thoracic wall. Finally, Emmel and colleagues ${ }^{3}$ showed that performing thoracotomy at a very young age (under 1 year) increases the risk of subsequent scoliosis. The relatively forceful spreading of the ribs and excessive stress on the costovertebral joints may account for this higher prevalence. 
TABLE 3. Comparison of studies

\begin{tabular}{|c|c|c|c|c|c|c|}
\hline Study & Patients, $n$ & $\begin{array}{c}\text { Age at operation, } y, \\
\text { mean } \pm \text { SD }\end{array}$ & $\begin{array}{c}\text { Follow-up, y, } \\
\text { mean } \pm \text { SD }\end{array}$ & $\begin{array}{c}\text { Muscle-sparing } \\
\text { PLT }\end{array}$ & Scapula alata, $\%$ & Scoliosis, \% \\
\hline Present study & 31 & $0.1 \pm 0.2^{*}$ & $11.2 \pm 1.5$ & Yes & $3.6 \dagger$ & $7.4 \ddagger$ \\
\hline Bal et al, $2003^{2}$ & $49 \mathrm{CHD}$ & $3.8 \pm 4$ & 6 & No & 77 & 31 (3/5 with $\mathrm{CoA})$ \\
\hline Emmel et al, $1996^{3}$ & $21 \mathrm{CoA}$ & $<1$ & $\geq 9$ & No & 57.1 & NA \\
\hline Roclawski et al, $2012^{4}$ & $45 \mathrm{CoA}$ & 6.9 & 14.8 & No & NA & 46.6 \\
\hline Van Biezen et al, $1993^{5}$ & $160 \mathrm{CoA}$ & & 12 & No & NA & 22 \\
\hline Kucukarslan et al, $2006^{16}$ & 90 non-CHD & $4.2 \pm 2.91$ & $5.65 \pm 2.83$ & Yes $(n=40)$ & $12.5(\mathrm{n}=5)$ & $2.5(n=1)$ \\
\hline
\end{tabular}

$S D$, Standard deviation; $P L T$, posterolateral thoracotomy; $C H D$, congenital heart defect; $C o A$, coarctation of the aorta; $N A$, not available. *For the purpose of comparison, we used the average, although the median, as in Table 1 , would be more appropriate in describing our cohort. $\nmid \mathrm{n} / \mathrm{N}=1 / 28$. $\ddagger \mathrm{n} / \mathrm{N}=2 / 27$.

Our $7.4 \%$ prevalence of scoliosis compares favorably with any other reported results of posterior thoracotomy and even of angioplasty. Two patients in our cohort developed scoliosis, which does not appear to be related to the incision. One patient with other thoracic musculoskeletal deformities might have developed scoliosis spontaneously, and the other patient developed scoliosis on the right side, which was used by general surgeons to repair a concomitant esophageal atresia. Only a few studies have focused on this midterm complication. They showed how severe the musculoskeletal degradation after a thoracotomy might be (Table 3). In this regard, angioplasty proponents may claim a better musculoskeletal outcome. To illustrate this, Roclawski and colleagues ${ }^{4}$ compared the prevalence of scoliosis in patients treated for coarctation of the aorta surgically or by angioplasty. The difference- $-46.6 \%$ versus $16.6 \%$-was significant. A comparison of the results of that study with ours might be biased, because those studies involved older patients than ours, with an average respective age at intervention of 6.9 and 9.3 years in their 2 groups. In another mixed study, Kucukarslan and colleagues ${ }^{16}$ found a better rates, similar to ours, of $2.5 \%$ for scoliosis and $12.5 \%$ for scapula alata in 90 patients, 40 of whom had undergone a muscle-sparing approach. In their approach, the serratus anterior was spared but the intercostal muscles or the latissimus dorsi were not, as they were in ours.

Regarding winged scapula, the prevalence oscillates between $12.5 \%$ and $77 \%$ in published reports (Table 3). Such high numbers result from old approaches, when the thoracotomy incision was especially wide, encompassing half of the left hemithorax. Currently, this prevalence certainly ranges closer to $10 \%$ to $15 \% .{ }^{16}$ We encountered one such complication, which looked like a hernia of the scapula tip through a weakened muscle layer or through a loose adaptation of the latissimus dorsi muscle to the posterior aponeurosis. Today, we close our parietal muscular plane in 2 layers, fixing the scapula tip to the serrratus anteriosus and the latissimus dorsi again to its aponeurosis. This strengthened closure should prevent any further deformity of the left shoulder.
The majority of the previously reported studies (Table 3) focused on musculoskeletal outcomes after thoracotomy performed at a time when surgeons were using generously large incisions. The amount of muscle severed has been reduced "almost spontaneously" over time in most units, and the contemporary risk of developing a chest wall deformity is certainly lower than the figures reported in these historical series. At times, at the beginning of our experience and in older children, we have partially divided the latissimus dorsi, having always privileged the quality of the aortic repair, without seeing any negative effects on the child's final stature. Nonetheless, any disturbance of the forces applied to the thoracic wall in a growing child can have an impact. We believe that this hazard is minimized with our approach.

\section{Study Limits and Strengths}

This study has several limitations. First, it is a singlecenter retrospective study of a small sample size without a control group. We did not have a concomitant or historical control group that could be used for comparison and relied on comparisons with published reports, of which some were performed in earlier periods using techniques that were less respectful of tissue. Finally, the definition of scoliosis and winged scapula may have differed among studies, making the comparatives figures less robust. Nonetheless, we tried to include all the musculoskeletal complications in this study by selecting patients who had at least 4.5 years of follow-up, because scoliotic problems seldom develop before age 3 years. ${ }^{5}$

In conclusion, in our cohort, our minimally invasive approach that respects the chest wall muscles resulted in excellent musculoskeletal outcomes without compromising the hemodynamic results of coarctation repair.

\section{Conflict of Interest Statement}

The authors reported no conflicts of interest.

The Journal policy requires editors and reviewers to disclose conflicts of interest and to decline handling or reviewing manuscripts for which they may have a conflict 
of interest. The editors and reviewers of this article have no conflicts of interest.

We thank Dr Olga Romanchenko, Sibylle Domig Najand, and all the involved practitioners for their collaboration. We also thank the Multimedia Manual of Cardio-Thoracic Surgery for permission to use Figures 2-5.

\section{References}

1. Dave HH, Buechel ERV, Prêtre R. Muscle-sparing extrapleural approach for the repair of aortic coarctation. Ann Thorac Surg. 2006;81:243-8.

2. Bal S, Elshershari H, Celiker R, Celiker A. Thoracic sequels after thoracotomies in children with congenital cardiac disease. Cardiol Young. 2003;13:264-7.

3. Emmel M, Ulbach P, Herse B, Dalichau H, Haupt WF, Schumann D, et al. Neurogenic lesions after posterolateral thoracotomy in young children. Thorac Cardiovasc Surg. 1996;44:86-91.

4. Roclawski M, Pankowski R, Smoczynski A, Ceynowa M, Kloc W, Wasilewski W, et al. Secondary scoliosis after thoracotomy in patients with aortic coarctation and patent ductus arteriosus. Stud Health Technol Inform. 2012;176: 43-6.

5. Van Biezen FC, Bakx PA, De Villeneuve VH, Hop WC. Scoliosis in children after thoracotomy for aortic coarctation. J Bone Jt Surg Am. 1993;75:514-8.

6. Prêtre R, Sologashvili T, Pfister R, Nowacka A, Berset S, Myers PO. Multimedia Manual of Cardio-Thoracic Surgery (MMCTS). Muscle-sparing extrapleural repair of neonatal aortic coarctation. Available at: https://mmcts.org/tutorial/ 1147. Accessed December 18, 2018.

7. Dave H, Rosser B, Reineke K, Nguyen-Minh S, Knirsch W, Prêtre R. Aortic arch enlargement and coarctation repair through a left thoracotomy: significance of ductal perfusion. Eur J Cardiothorac Surg. 2012;41:906-12.
8. Kadner A, Dave H, Bettex D, Valsangiacomo-Buechel E, Turina MI, Prêtre R. Anatomic reconstruction of recurrent aortic arch obstruction in children. Eur $J$ Cardiothorac Surg. 2004;26:60-5.

9. de Divitiis M, Rubba P, Calabrò R. Arterial hypertension and cardiovascular prognosis after successful repair of aortic coarctation: a clinical model for the study of vascular function. Nutr Metab Cardiovasc Dis. 2005;15:382-94.

10. Daniels SR. Repair of coarctation of the aorta and hypertension: does age matter? Lancet. 2001;358:89.

11. Zehr KJ, Gillinov AM, Redmond JM, Greene PS, Kan JS, Gardner TJ, et al. Repair of coarctation of the aorta in neonates and infants: a thirty-year experience. Ann Thorac Surg. 1995;59:33-41.

12. Früh S, Knirsch W, Dodge-Khatami A, Dave H, Prêtre R, Kretschmar O. Comparison of surgical and interventional therapy of native and recurrent aortic coarctation regarding different age groups during childhood. Eur J Cardiothorac Surg. 2011;39:898-904.

13. Kaushal S, Backer CL, Patel JN, Patel SK, Walker BL, Weigel TJ, et al. Coarctation of the aorta: midterm outcomes of resection with extended end-to-end anastomosis. Ann Thorac Surg. 2009;88:1932-8.

14. Durning RP, Scoles PV, Fox OD. Scoliosis after thoracotomy in tracheoesophageal fistula patients. A follow-up study. J Bone Jt Surg Am. 1980;62:1156-9.

15. Feiz HH, Afrasiabi A, Parvizi R, Safarpour A, Fouladi RF. Scoliosis after thoracotomy/sternotomy in children with congenital heart disease. Indian J Orthop. 2012; $46: 77-80$.

16. Kucukarslan N, Kirilmaz A, Arslan Y, Sanioglu Y, Ozal E, Tatar H. Muscle sparing thoracotomy in pediatric age: a comparative study with standard posterolateral thoracotomy. Pediatr Surg Int. 2006;22:779-83.

17. Reckles LN, Peterson HA, Weidman WH, Bianco AJ Jr. The association of scoliosis and congenital heart defects. J Bone Joint Surg Am. 1975;57:449-55.

Key Words: coarctation of the aorta, muscle-sparing approach, children 